\title{
Succeeding in Foreign Language Study: Teachers and Students Standpoints
}

\author{
Larisa Vladimirova ${ }^{1 *}$, Rais Safin $^{2}$, Daria Ivanova $^{3}$, and Tatyana Litvina ${ }^{4}$ \\ ${ }^{1}$ Kazan Federal University, Preparatory School for the Foreign Students, 420111 Kazan, Kazan, 34 Levo-Bulachnaya str., \\ lvladimi58@mail.ru \\ ${ }^{2}$ Kazan Federal University, Preparatory School for the Foreign Students, 420111 Kazan, Kazan, 34 Levo-Bulachnaya str., \\ rsafin56@mail.ru \\ ${ }^{3}$ Kazan Federal University, Preparatory School for the Foreign Students, 420111 Kazan, Kazan, 34 Levo-Bulachnaya str., \\ daria624@yandex.ru \\ ${ }^{4}$ Kazan Federal University, Preparatory School for the Foreign Students, 420111 Kazan, Kazan, 34 Levo-Bulachnaya str., \\ litvina_ta@mail.ru
}

\begin{abstract}
The paper considers views of teachers and international students on effectiveness of language acquisition. The study represents the results of original experiment conducted among international students from the various institutes of Kazan Federal University. Students were requested to determine the priority of the following factors and explain the choice: a role of motivating anxiety for learning foreign language; a role of language abilities and talents of international student; a role of professional and personal characteristics of foreign language teacher; a role of methods, techniques and technologies of teaching; importance of studying within environment of a target language. Views of experts and international students on priority of impact of various factors of the foreign language teaching differed. The only factor where the opinions of teachers and students were the same, turned out to be the role of motivation. However, comparative analysis of factors of effectiveness in studying from the point of view of different and in the same time unified subjects of this process shows that the whole complex of factors must be taken into account. The results of the conducted study inevitably prove the necessity of considering the students' opinion on the process of teaching, and corresponding correction

of

teachers

activities.
\end{abstract}

\section{Introduction}

It is a bit funny that we have started up writing the paper on raising the effectiveness of the study in the field of foreign languages (the Russian, first of all) and the role of students' motivation, having been ourselves partially inspired by accurately the opposite: namely, witnessing big groups of international students who do not show much interest in the study itself except for tremendous anxiety about receiving "the paper" - as the Russians used to call any kind of document, Diploma, Certificate. One names it as a worthy reward for the time spent polishing school benches. Anyhow, all our students showing good and not very good progress, motivated and not so much motivated for study, need our attention and every-day labor. In addition to this, some more observations, connected to such mighty things like interests of nation, globalization, etc. are in effect. Globalization, gradually integrating the political, economic, cultural spheres of many countries, on the one hand, and the desire of specific states to increase their competitiveness in the international market of educational services, on the other hand, inevitably dictates a significant increase in the role of teaching and learning foreign languages throughout the world. One can read more about it in, for example, $[1,2]$.

The points of view on the role of the Russian language in the world and prospects for its study in the world community are radically different.

Some believe that the Russian language has a good future. So, in attempts to determine shapes of a language of the next generation, many researchers analyze materials of various social networks and use of Wikipedia. Without single doubt, the English language occupies the first position here. But as for the rest of the languages, the situation is radically different: in social networks and Wikipedia, Russian is ahead of all other languages - it is in the second place after, of course, English, with Spanish and French coming up next. Such widespread languages as Hindi, Arabic and Chinese fall far behind.

Thus many researchers come to the following conclusion: if a modern young man wants to understand and to be understood in international communication, English, Spanish, French and Russian should become his priority for study. Experts are sure that it is more promising to learn exactly these languages.

However, some other linguists, on the contrary, are extremely pessimistic on the perspectives of the Russian 
language. Despite the fact that Russian is one of the most widely spoken languages in the world - geographically and by the number of its native speakers - its popularity is waning catastrophically. Researchers note that as early as by the end of the 1980s, about 350 million people spoke Russian, but after the collapse of the Soviet Union, this number began to decline rapidly - by the year 2000, it had decreased by almost 50 million people. According to the Russian government, the total number of those who spoke Russian was about 260 million people in 2014. Some experts believe that the Russian language by the number of speakers ranks eighth in the world after English, Chinese, Hindi, Spanish, Portuguese, Bengali and Arabic at the moment. The number of foreigners studying Russian right now is about 11 million people.

According to experts, the present trends will keep on going: the Russians, unfortunately, will be losing popularity. Due to the recent political events, there may be a small surge of interest, but, according to British linguist David Graddol, expert on the future of languages, most of those who use two or more languages will choose English as the second language by 2050 [3]. No matter how sad it is, it will not be possible to return to former glory of the Russians, alas.

Thus, an objective tendency to decreasing of demand for the Russian language cannot stay unnoticed. This tendency makes us think about what can be done to maintain interest in Russian as a second language, both in remote and in the near overseas. According to the policy of the Council of Europe, some of its priority principles in the field of language education are the following: a globally integrated approach to the policy of language education; respect for other languages and multilingualism of other people and awareness of the value of other languages regardless of their role in society; availability of multilingual education; the right to learn different languages and gaining the linguistic competences of any levels.

All of the above can contribute to understanding of why a person makes choice of the language to learn and how he masters it; and in turn it is directly related to the topic of our study, which considers the difference or commonality of the standpoints of the two subjects of the educational process (teachers and students) concerning evaluation of priority factors of success of teaching and studying of the foreign language.

\section{Experiment and results}

We conducted a methodical experiment among international students and trainees of all levels at various institutes of Kazan Federal University (Russian Federation), who had gained the advanced or near to it level of Russian language proficiency. International students were asked to prioritize the following factors, which, in their opinion, affect the success of learning a foreign language, and, if possible, comment on the choice: 1) motivation for studying Russian as a foreign language; 2) linguistic abilities and talents of an international student; 3) professional and personal qualities of a teacher of Russian as a foreign language (abbreviation RFL will stand for Russian as a Foreign Language hereafter in the text); 4) methods, techniques and technologies for teaching a foreign language; 5) teaching in the country of the studied language (i.e. within the language environment) and some others. Despite the predictability of some of the answers and some of our expectations, the results of the survey largely supplemented, and in some cases even changed our vision of the problem under study.

The final rating compiled by the students participating in the experiment is as follows:

1) motivation for studying RFL;

2) studying in the country of the studied language; RFL;

3) methods, techniques and technologies in teaching

4) professional and personal qualities of the RFL teacher;

5) linguistic abilities of international student.

Now, let us consider each of the aspects of success in the study of RFL in the sequence that the students defined, supplying each chapter with some features of the methodology of teaching of RFL and information on our personal experience of teaching it.

1. Role of motivation in studying RFL

Most of the international students put this factor in the first place. In this issue, the standpoints of the experts who teach RFL and those who study it match. In the set of conditions affecting the success of training, motivation takes a special place as a factor giving activity meaningfulness and dynamism.

Motivation determines the productivity of any activity, including language training, and is its natural component. Importance of the motivational factor in the effectiveness of mastering a foreign language is emphasized by both Russian and foreign experts on teaching $[4 ; 5 ; 6]$. Check out this, for example: "To date the task of foreign language practical acquisition is complicated by a number of reasons. The reduction in the number of class hours, the weak motivation of the educational process, the lack of effective teaching methods create difficulties for a foreign language study in the amount corresponding to the tasks of professional activity. Therefore, the actualization of the principle of conscious and motivated linguistic material mastering should become a decisive factor in teaching a foreign language for professional communication. It is the question of the development of cognitive and professional motives as constituting factors for ensuring the educational process effectiveness" [7]

The motives or reasons for learning a language different from the mother tongue can be very different. Let us name some.

- Crucial changes taking place in the country, and actively covered by the world mass media can draw attention to and interest in the language spoken there. E.g., a sharp increase in interest in studying of the Russian language in the early nineties was a kind of a response to perestroika, which Mikhail Gorbachev announced in the Soviet Union in 1985.

- The social order or requirements of the state and society, including the political interest of the state in a 
particular language, forcing interest in its study. Social orders in different countries can be different, because they directly depend on the political, economic and social and cultural features of the country's development at any historical period. "Approaches, methods and content of training change because the society sets different goals and objectives for teaching a foreign language in different historical periods and various social and economic conditions" [8]; "The new social order of a modern society is to teach a foreign language not only as a means of communication, but also to form a professionally competent polylingual and multicultural personality, ready for intercultural professional communication" [9].

- Personal interest in the country of the studied language can also become an incentive for learning the language. As for the Russian language itself, several groups of students who wish to study it can be distinguished here.

The first group of students include those who are in love with the Russian literature; they want to read Tolstoy or Chekhov in original. The others want to obtain information about the history of Russia and its modern life and events through studying the language.

The second group is made by the foreign businessmen who turn to studying the Russian language due to the need to use it as an instrument of business cooperation with Russian-speaking partners in Russia and other CIS countries.

The third group includes numerous nationally mixedmarried couples, where one of the spouses is a native speaker of the Russian language.

Children and grandchildren of the ethnic Germans from the Volga region, Siberia and Kazakhstan, who moved to Germany to stay during the Russia's difficult 1990s and do not want to lose their Russian and connections with Russian culture, make the fourth group.

The fifth group includes the native Russians whom different circumstances led to become the citizens of other countries. They want their children to learn their native language, but the country where they permanently reside, sometimes doesn't agree on that. An example is Latvia, where in April and May, 2018 mass protests against the law prohibiting the use of Russian language in Latvian schools took place.

- Motivation can be random.

One of the American teachers of Russian testifies that the number of students at his school has increased significantly when in the middle of the 2000s talented Russian hockey player Alexander Ovechkin started playing for NHL.

The Swiss student, who came to Kazan Federal University for a semester training program, wrote in her comments, "In Switzerland you wake up in the morning and know exactly what is going to happen today. It's as if they have already drawn up a plan for you in advance. It's so boring. And in Russia everything is vice versa: here you wake up and do not know what awaits you at all. Even the morning news is interesting to listen to. At home, I never listened to them. I want to live in Russia!"

- Personal ideas of the foreigners about beauty, euphony, aesthetic appeal of the language being studied, etc. Experts in teaching believe that the motivation for learning a language is greatly influenced by the teacher. This motivation is high at the beginning of the learning process, and in the future tends to weaken, but, as one student correctly remarked, "interest is the best teacher". Here we go with more excerpts from students' comments on the matter. "Interest is everything!" "It's not so important what kind of motivation the foreign language student has; it's important how strong it is". "The most important motive is an interesting lesson, when you do not want it to end". "You have to understand why you need to learn this language, and try to fall in love with $i t^{\prime \prime}$.

Having considered the motives for learning a foreign language, it would be natural to ask the question about "what can demotivate the foreign student who has already started studying Russian in Russia?" Here are some possible answers.

- The legendary "difficulty" of the grammar of the Russian language, the lack of rapid and visible success in overcoming the difficulties.

- Conditions of study at home University different from those in Russia, i.e. using or not using the students' mother tongue during the language class; the number of students in the class; presence or absence of students with the high and low language proficiency in the same class, etc.

- Religious traditions can also play a demotivating role. For example, many students from Iran and some other states with strict Muslim rules can leave the classroom at certain times without the teacher's permission to perform the prayer rite, and on Friday they do not attend classes at all, justifying this by a need for an obligatory visit to the mosque, which, of course, is absolutely not allowed by the internal regulations of Russian educational institutions.

- Relations with the Russian language teacher sometimes do not work out due to the teacher's inadequate professional competence, incorrectly chosen teaching methods without regard for the national and personal characteristics of students, including constant criticism and lack of praise for a student.

- Significant differences between the native culture of the alien and the culture of the country of instruction.

- Political predilections of students within a multinational group, where the students from countries with different political systems study together can be an additional source of demotivation. As an example, let us cite the case of a Chinese student who had to make presentation about Kazan and Kazan Federal University on the Russian language instructor's demand. During the presentation, he proudly mentioned the name of Lenin several times, which is quite reasonable, since UlianovLenin studied in Kazan at the end of the 19th century. This caused an unexpected reaction from students from Germany and some other European countries: they began to laugh loudly. It is clear that the student from China, insulted in his political beliefs, did not attend classes for several days and even thought about returning to his homeland. However, thanks to efforts of the Russian language teacher, he continued to study in Russia, having changed the training group. 
- Lack of parental or other control over the general and academic discipline - attending classes, presenting homework on time, etc., to which students are accustomed thanks to previous educational experience at home.

- Unusual climatic and living conditions in the country of the studied language, etc.

Different categories of students of RFL have different communication needs. But, no matter how broad the range of motives, interests and needs of students is, it is necessary to remember that most of them learn Russian as a tool for communication in Russian. Studying the motivational sphere of the student's personality is important not only from the point of view of the student's desire and readiness to learn the language, but also from the point of view of teacher's choice of individual style of educational activity and prevention of difficulties typical for a particular international student.

2. Studying in the country of the language being learnt (within the language environment)

When studying the foreign language, motivation is one of the key factors, but not a sufficient condition for building up linguistic, social and cultural competence of a trainee. The desire of a student to learn a foreign language must be accompanied by his personal attitude to the chosen language, preferably verified by his presence in the country of the studied language. In our opinion, this set of factors can contribute to strengthening of the interest in the process of the foreign language acquisition. "As the most important factors for the effective foreign language learning are the language environment and the motivation, thus the development of new motivational language learning environments, including virtual reality (VR) and 3D environment, is the basic elements of the learning process" [10].

The educational process must be communicative: this principle is considered as an initial methodical category. This category determines the importance of building the process of foreign language education as a process of communication. From our point of view, teaching a language ideally should be, on the one hand, the study of the language system and, if possible, be likened to the actual process of communication. On the other hand, teaching a language must take place within a direct contact with the native speakers, that is, must go along with the natural every day practicing. This is facilitated by staying and studying in the language environment.

Education in the country of the language being studied is a methodological principle that recognizes the important role of the language environment as a learning factor and as a condition that increases the effectiveness of teaching a foreign language. Staying in the country of the studied language enables the foreign student to get linguistic and general social and cultural experience. "When a student enters into a new culture..., he or she shall also get acquainted with the elements of national culture: spiritual life, art, national traditions, politics, and economics. Even with a high level of foreign language knowledge, the communication successfulness may be reduced due to ignorance of the elements of extra linguistic reality". In addition, the increase in all kinds of international contacts and the influx of foreign students in Russia are one more evidence that the study of the Russian language as a foreign language should be based not only on the way of traditional familiarization with the phonetic, grammatical and lexical aspect of the language, but also with the culture and mentality of the country of the language studied" [11]. One of the ways of acquiring such experience is the visiting programs of training of foreign students in Russia - when the students from the overseas universities are included into the Russian university curriculum for a semester or two and study along with the Russian students in ordinary students' groups.

Our long-term experience in teaching Russian as a foreign language both at the Russian Universities and overseas (i.e., in China, the USA, Germany, Spain and other countries) proves that international students in Russia and the same students at home require different approaches in terms of teaching methods and techniques. This is not surprising, since the cultures of Russia and those of the home countries of foreigners, as well as the education systems, differ significantly.

The main differences in teaching RFL in the educational space of Russia and outside it boil down to the following:

- specific features of the students' anxiety to learn the language abroad and in Russia;

- significant difference in the degree of use of the native language of students during the classes in Russian and foreign educational institutions. In Russian universities they speak, as a rule, only Russian. An exception may be the initial stage of language learning, when, in case of great necessity, English is used as the language of international communication, provided that all students are proficient in it;

- teachers of Russian outside Russia work mainly with the mono-ethnical groups. At Russian universities there are also groups consisting of students of only one nationality (for example, only Chinese, Germans or Iranians), but for the most part the specifics of the educational process dictate the formation of groups of students from different countries and different nationalities. This entails both the pros and cons of teaching RFL, however, in our opinion, there are more positive moments in this situation;

- in the country of the studied language, teachers usually go from reality to the text, but in a foreign language environment the drift from text to reality works most often;

- different sets of aspects of a language and types of speech are activity used when teaching in the Russianspeaking educational environment and outside it. At foreign universities, more attention is paid to grammar, vocabulary and receptive types of speech activities that seems inevitable under the conditions of non-Russian linguistic environment;

- different quality and the number of training parameters;

- excessive standardization of knowledge obtained by RFL students at universities outside of Russia;

- specifics of higher education in a particular country: different organizational forms of teaching Russian in 
Russian and foreign educational institutions, the number of students in language groups, various forms of intermediate and final control, etc. Naturally, the longer the period of stay in the language environment, the more noticeable is the effectiveness of such training. Awareness and comprehension of this experience of obtaining knowledge of the language, culture and everyday life received directly in the country of a target language (as to say, "first-hand"), makes the formation of a multicultural individual more successful.

Understanding the positive influence of the linguistic environment on the effectiveness of learning foreign languages is evidenced by the fact that more than a third of the interviewed students placed the factor of the learning potential of the Russian linguistic environment in the second place right after the motivation:

"When you are in Russia, you live in the Russian language". "The language environment forces you to use the language round the clock (and even think in it!) - not only during the classes". "Language is a living phenomenon; it can't be studied only in the classroom or from the books". "When a student comes to Russia, he understands why he learns Russian". "In the language environment you learn even against your will".

A very important observation, in our opinion, was made by an intern from Italy: "Being in a language environment is a moment of confirmation or denial of one's personal idea of the country and of one's knowledge of the language".

Thus, the language environment is a kind of verification, a "moment of truth" for the international students of RFL. RFL

3. Methods, techniques and technologies in teaching

Significant changes that are currently taking place in society entail the need for continuous improvement of methods, techniques and technologies of teaching the foreign languages. "Now more and more attention is given to group project work, the case-study method, presentations, round tables, and discussions. Such forms of work solve the task of the modern time - to form foreign-language professional competence - the ability and readiness of future specialists to solve communication and professional tasks, carry out search and analysis of information, work with technical literature and documentation in a foreign language in the professional field" [12]. The issues of improving the quality of education in the field of RFL have always been and remain one of the main priorities. According to the RFL methodology experts, the shape and content of teaching RFL in Russian higher education institutions is determined by a communicative approach in conjunction with the consciously practical comprehension of linguistic phenomena.

However, at the present time, RFL experts say that special attention is paid to the manners and strategies of instruction, depending on the differences between the students. In recent times, a shift in focus has occurred: from teaching to training, from a teacher to a student. Modern approaches in methodology are based on understanding of how different categories of individuals master a foreign language (learning manners) and what is needed for its mastering to be more successful (learning strategies). All of the above-mentioned is confirmed by the students' comments on the effectiveness rating of the RFL study factors.

"I do not like when the teacher sits at the lesson and says:" Read the rule! Translate the text! Answer the questions! Do an exercise!" This we can do at home. I like it when a teacher creates different situations during the lesson and talks to us not as students, but as people".

A correctly selected training method, according to interviewed foreigners, is "half the success", as it helps to "mobilize the activity of students", "to reveal their potential," and "facilitates the interactivity of the learning process of the language." It is interesting that, without knowing the theory of RFL methodology, international students intuitively distinguish teaching techniques and learning techniques, emphasizing the importance of the latter. In their opinion, the role of a teacher and the methods chosen by him are of great importance, but no less important is the role of the student himself in the process of learning the language. In fact, we are talking about what experts call using the term "learning style":

"The teacher's help and methods are very valuable. But students must choose the appropriate methods for themselves". In their comments, international students have not left aside modern information and communication technologies that provide new opportunities and platforms for studying RFL:

"I like that every day I can communicate in Russian over Whatsapp with classmates and even with a teacher of Russian. She always answers me. We exchange messages not only about grammar, but about life".

Meanwhile, it should be recognized that the methods and techniques of teaching RFL are important, but relatively minor; a productive deviation, reasonable creativity should be welcomed. An innovative trend here lays within the optimal combination of all existing methods, techniques and modern information and communication technologies. We believe that there is no method that could be considered universal in principle. The only correct, therefore the best, methods are those methods and techniques that give the best result. In our opinion, the most effective method is the one that does not teach the language much, but teaches how to study. RFL

4. Professional and personal qualities of a teacher of

Modern theory of education management allows us to compare the teacher of RFL with a manager whose activities, in addition to teaching, include the functions of an administrator, an organizer, an expert, a psychologist, a mentor and some others. Teaching technologies, personal qualities, cooperation with students serve as a basis for successful educational management.

According to experts, the psychological guideline aimed at studying a foreign language is determined not only by the abilities and personal merits of students, but in many ways by the teacher and the general atmosphere created by one in the class. Undoubtedly, the most important thing for the RFL teacher is one's professional competence. In addition, the teacher's individual 
psychological abilities in implementation of his professional choice play an important role. Among the many factors that positively influence the effectiveness of instruction in RFL, the following characteristics of a RFL teacher are named among the most significant: ability to present the Russian language as a harmonious and understandable system of interrelated linguistic elements; ability to create favorable atmosphere of communication, atmosphere of success and sense of progress in learning, which helps to remove the communicative barriers; maintaining high motivation to learn a foreign language; real interest in a language student as an equivalent partner in the educational process; taking into account the individual characteristics of students; i.e. student's aptitude to cognitive-linguistic or communication and speech type of mastering the language; adequacy of the teacher's reaction to the emotional manifestations of different nature (national, age, religious, etc.) coming from the students; monitoring of the results of students' education; timely reacting to them; optimal ratio of productive and reproductive types of speech activity in organizing the process of mastering the Russian language; and some others.

Many students who participated in our survey share the RFL experts' standpoints emphasizing importance of the role of the teacher, especially at the initial stage of language training: "I had an excellent teacher. He was the main reason why I began to learn Russian at all".

"My first teacher of Russian was from Russia. We've been friends with him ever since. He was cool!"

Here we go with more respondents' statements that show understanding of importance of the teacher in the foreign language learning process: "A good teacher teaches not only language, but how to live". "A teacher of foreign language greatly affects the life and future of students". "Teacher is a guide. As with a good guide, the trip can be interesting, exciting, useful, and with a good foreign language teacher, students easily notice the beauty of the language being studied ". "A teacher is the first person who serves a bridge between students and other people, another language, another culture". "The language and the teacher can be compared to a fireside and a person maintaining the fire. The better he does it, the more people who want to get warm at this fire".

A female student from China cited a Chinese proverb: "The teacher only opens the door, through which you must go yourself". In our opinion, this confirms the fact that a good teacher is not the only condition for successful study.

5. Linguistic abilities of foreign language students.

"At the beginning of the 21 st century, the human factor of basic paradigmatics has predetermined the most important features of modern linguistics: anthropocentricity, functionality, cognition and integrity. This direction of linguistic research led to the study of the functioning of the language in interaction with the person, with his material and practical and spiritual activity according to the following positions: sociolinguistic, psycholinguistic, cognitive, philosophical" [13]. The question of ability to learn other languages is one of important, but unfortunately insufficiently studied, despite its relevance to psychological research. In the practice of teaching RFL, we take into account the fact that there are at least two basic psychological types of students that roughly can be defined as communicative (tending to communication and speech) and non-communicative (cognitivelinguistic), the main differences between those types can be summed up as follows.

Students that belong to the first of the abovementioned types in most of the cases do not need detailed theoretical explanations; do not experience special difficulties in mastering foreign language in the process of verbal communication; formally refer to the performance of imitation, substitution and transformation exercises, but with interest perform reproductive, situational and gaming tasks that are communicative in nature; participate in educational or real communication easily.

For the second type students it is easier to learn the language in a conscious way; they need to carefully comprehend all the features of the new language material, so that, unlike those of the first type, they need to be explained the grammatical theory of the language for a long time and in detail. They perform formal language exercises with pleasure, though they face difficulties with communicative tasks; due to certain problems of psychological origin, they do not easily develop speech skills, especially in the field of such productive kind of speech activity as speaking; treat with interest various forms of written assignments.

Unfortunately, in modern methods of teaching RFL, shortage for an optimally developed individual-personal typology of students is still felt. This kind of typology could have allowed creating flexible models of teaching RFL. As for our experiment, practically all its participants ignored the significance of the factor of linguistic abilities, placing it in the last place; only three students rated it as a priority condition for the effectiveness of mastering RFL. Some foreigners expressed the opinion that linguistic abilities of students affect only the rapidness of learning a foreign language.

Many students agreed that success in learning foreign language is not directly related to the language abilities, but depends on the desire to master this language, perseverance and efficiency: "Ability is work; the more you work, the more you succeed". "I do not have the ability", - so only those students who do not like to practice say. If someone really wants, he can learn everything, even Russian and Chinese!"

Meanwhile, from the point of view of teachers, experts on teaching methods and psychologists, the development of speech skills and abilities in the field of the language being studied varies among students of different categories. Among the factors influencing the success or failure of this process, the most significant ones are the psychological characteristics of the individual, which are: education (and "educatedness"); age; prior language experience.

However, experts have proved that the educational level of students and the linguistic experience accumulated by them, that is, knowledge, skills and abilities in the field of one or several languages, is the 
determining condition for the effectiveness of mastering new language. It is interesting that this feature was pointed out by the intern-physicist from Switzerland, who could speak several foreign languages, but obviously was not an expert in language teaching: "The more languages a student already knows, the easier it is for him to learn a new foreign language. Every next language goes into the soul by itself".

It should be said that some other questions were offered to students in the questionnaire: the complexity or simplicity of the grammatical structure of a foreign language when chosen for study; traditions of study of foreign languages in students' home country; the role of additional tools and techniques of teaching and study etc., but the survey participants rated them as not particularly significant. Nevertheless, some comments on these factors demonstrate methodically useful results. Among the teaching tools, students estimated the role of visual design of textbook as important as its content, or reading and analyzing works by Soviet authors that are not the most popular abroad, such as I. Ilf and E. Petrov, A. Averchenko, and others. This matches the standpoint of the teachers of RFL $[14,15]$.

\section{Conclusion}

The final comparison of the views of RFL methodologists and foreign students on the factors of the effectiveness of learning the Russian looks as follows.

The roposed sequence of conditions for the success of mastering the RFL is:

1) reasons for studying Russian as a foreign language;

2) linguistic abilities of an international student;

3) professional and personal qualities of a teacher of Russian as a foreign language;

4) methods, techniques and technologies for teaching Russian as a foreign language;

5) learning in the country of the studied language (within the language environment).

Students rating:

1) reasons for studying Russian as a foreign language;

2) learning in the country of the studied language (within the language environment);

3) methods, techniques and technologies for teaching Russian as a foreign language;

4) professional and personal qualities of teacher of Russian as a foreign language;

5) linguistic abilities of an international student.

As the analysis of our survey shows, a motivational factor is the only one in which the opinions of teachers and students (about 90\% of the participants of the experiment) coincided. This factor took the unconditional first place: both subjects of the educational process understand its importance.

The foreigners attach great importance to the condition of studying in the country of studied language (37\% of respondents), since many of them study RFL outside the Russian educational space and understand that inclusion in a genuine foreign environment makes it possible to develop and improve communicative abilities in the language being studied.

Students gave the third place (almost $30 \%$ of those participating in the survey) to methods and techniques of teaching the language, since methods, styles and strategies of instruction, modern information and communication technologies stimulate students' cognitive activity, have a positive impact on maintaining motivation for learning and, what is very important, on the ability of students to solve professional problems in Russian. However, the authors, based on the long experience of teaching RFL, insist that the most effective method is the one that teaches not only language itself but teaches how to learn it and how to use it for learning.

International students estimated significance of the professional and personal characteristics of teacher of RFL lower than it was suggested, nevertheless, they understand that the teacher is important not only as a language teacher, but also as a mentor in life.

Neglecting the factor of ability to study and learn languages by the questioned was quite surprising, although in the practice of teaching RFL teachers give it, as many experts admit, much more importance. Apparently, students intuitively understand that a lack of talent or linguistic knowledge and skills can be compensated by high positive motivation, by learning in language environment, by properly chosen methods.

Thus, comparative analysis of factors of effectiveness in studying RFL from the point of view of different and at the same time unified subjects of this process shows that the whole complex of factors must be taken into account. When assessing the priority of impact of certain factors on the success of teaching RFL, one should remember that an unambiguous answer to this question is objectively difficult; the more relevant our experiment on determining the conditions for optimizing the process of learning RFL appears to be.

\section{References}

1. G. Crookes, R.W. Schmidt, Language Learning 41, 469-512 (1991)

2. D. Block, ELT Journal, January, 287-304 (2004)

3. D. Graddol, The future of English? (British Council, Jan. 1997)

4. I.V. Aleshchanova, E.V. Morozova, N.A. Frolova, M.R. Zheltukhina, Proceedings of the 7th International Scientific and Practical Conference "Current issues of linguistics and didactics: Advances in Social Science, Education and Humanities Research 97, 19-24 (2017)

5. P. Pimsleur, L. Mosberg, A. Morrison, Modern Language Journal 46 (4), 160-170 (1962)

6. A.-M. Masgoret, R.C. Gardner, Language Learning 53(1), 167 - 210 (2003)

7. I.V. Aleshchanova, E.V. Morozova, N.A. Frolova, M.R. Zheltukhina, Proceedings of the 7th International Scientific and Practical Conference "Current issues of linguistics and didactics: 
Advances in Social Science, Education and Humanities Research 97, 20 (2017)

8. E. Korobova, D. Mironova, I. Kardovich, Konysheva M., Proceedings of the 7th International Scientific and Practical Conference, Current issues of linguistics and didactics: Advances in Social Science, Education and Humanities Research 97, 119 (2017)

9. E. Korobova, D. Mironova, I. Kardovich, Konysheva M., Proceedings of the 7th International Scientific and Practical Conference, Current issues of linguistics and didactics: Advances in Social Science, Education and Humanities Research 97, 123 (2017)

10. V. Dobrova, K. Trubitsin, P. Labzina, N. Ageenko, Yu. Gorbunova, Proceedings of the 7th International Scientific and Practical Conference "Current issues of linguistics and didactics: Advances in Social Science, Education and Humanities Research 97, 19-24 (2017)

11. I.R. Galiulina, V.N. Yapparova, O.V. Starostina, Modern Journal of Language Teaching Methods, Special Issue: December 2016, 37-42 (2016)

12. E. Korobova, D. Mironova, I. Kardovich, Konysheva M., Proceedings of the 7th International Scientific and Practical Conference, Current issues of linguistics and didactics: Advances in Social Science, Education and Humanities Research 97, 119 (2017)

13. A.A. Isakova, Proceedings of the 7th International Scientific and Practical Conference. Current Issues of Linguistics and Didactics: Advances in Social Science Education and Humanities Research 97, 4 (2017)

14. L.V. Vladimirova, Proceedings of ROPRYAL 5-th Congress 5, 1677-1681 (2016)

15. R.N. Safin, Proceedings of Kazan University, Humanities series 155(5), 172-178 (2013) 